\title{
Novice nurse educators' lecture room instructional management competence
}

\author{
M Dürrheim, D Litt et Phil, Department of Advanced Nursing Sciences, Unisa \\ VJ Ehlers, D Litt et Phil, Department of Advanced Nursing Sciences, Unisa
}

\section{Abstract}

The lecture room instructional management competence (LRIMC) of novice nurse educators (NNEs) in the Republic of South Africa (RSA) was investigated by means of a quantitative exploratory survey using questionnaires. The findings indicated that NNEs benefited from mentors' guidance, experienced reality shock on entering their first teaching situation, and lacked LRIMC - according to the perceptions of the NNEs themselves, their students and their mentors. NNEs could benefit from effective orientation programmes and from ongoing in-service education programmes as well as from the availability of mentors assigned to specific NNEs.

\section{Opsomming}

Die lesingsaal onderrig bestuursbedrewenhede (LRIMC) van nuwe verpleegdosente (NNEs) in die Republiek van Suid-Afrika (RSA) is ondersoek deur gebruik te maak van ' $n$ kwantitatiewe verkennende opname waarin vraelyste benut is. Die navorsingsresultate dui aan dat NNEs baat gevind het by die begeleiding van hulle mentors, werklikheidskok ervaar het met die toetrede tot hulle eerste onderrigsituasie, en dat hulle bedrewenhede (LRIMC) gebrekkig was. NNEs kan baat vind by effektiewe oriëntasie programme en volgehoue indiensopleidings programme. Mentors wat aan spesifieke NNEs toegewys word, kan die aanpassings van NNEs vergemaklik.

\section{Introduction and background information}

Nurses form the largest group of health care professionals in the Republic of South Africa (RSA) where health problems such as acquired immuno deficiency syndrome (AIDS), tuberculosis (TB), escalating numbers of trauma patients resulting from violence and motor vehicle accidents and increasing numbers of very old people pose ever greater challenges to the health care sector to meet these diverse health care needs. In addition to these health care challenges, the fast rate of development of medicine, as a result technological and scientific advances, necessitates continuous changes in the health care sector, in nursing and in nursing education (Halstead, Rains, Boland \& May 1996:413).

Professional nurses and student nurses in the RSA are faced with the challenge of keeping abreast of all these changes and meeting the health care demands. Changes in the RSA's educational system placed additional demands on nursing education. The major role of the nurse educator in the RSA, and internationally, has changed over the past decade from mainly transmitting knowledge to that of acquiring, transmitting and applying knowledge. Students have changed from passive recipients of facts to active participants in discovering and applying knowledge. The lecture room instructional management competence (LRIMC) of nurse educators (NEs) is of pivotal importance to the professional development of student nurses and the quality of the nursing care rendered to the citizens of the RSA.

No comprehensive set of generic roles, outcomes and competences for instructional management of nurse educators could be traced in the literature. No research results could be traced about the LRIMC of novice nurse educators (NNEs) in the RSA.
The major purpose of this research was to investigate how the NNEs, their students and their mentors perceived the LRIMC of these NNEs. This was deemed to be essential because the competence of nurse educators has a direct influence on the education of students, the profession and the nursing care rendered to the public (Davis, Dearman, Schwab \& Kitchen 1992:159).

\section{Literature overview}

The University of South Africa's library consulted the following data bases to obtain relevant research reports:

Medline Express

CINAHL

NISC Disc report of South African studies 1987-1998 ERIC.

The literature sources were reviewed, analysed and synthesised into the following sections in the research report:

- $\quad$ perspectives on nursing education (including social variables influencing nursing eduation, adult teaching and learning theories impacting on nursing education)

- a general perspective on the nurse educator (including the training of nurse educators in the RSA, NNEs' experiences of reality shock and their needs for mentorship, models of professional development for the NNE)

- $\quad$ the nurse educator as an education, training and development (ETD) practitioner (emphasising the pre-, inter-, and post-active tasks of the NNE as well as the administrative tasks of the NNEs). An ETD model was proposed, serving as a basis for identifying the competencies needed by the nurse educator to be an effective ETD practitioner. An analytical study was undertaken, using nursing education and adult edu 
cation in the literature research. Roles, outcomes and competencies necessary for LRIM were identified, constituting the evaluation criteria used in the questionnaires to obtain NNEs', students' and mentors' perceptions about the NNEs' LRIMC.

Seventeen roles pertaining to LRIMC were identified and adapted from similar models of the Electricity Commission, the National Training Board, Halstead et al and Curzon. The following roles for LRIM were identified:

- $\quad$ Administrator
- $\quad$ Assessor
- $\quad$ Designer
- $\quad$ Evaluator
- $\quad$ Learning facilitator
- $\quad$ Leader
- $\quad$ Marketer
- $\quad$ Instructional material developer
- $\quad$ Needs analyst
- $\quad$ Researcher
- $\quad$ Manager of instruction
- $\quad$ Community developer
- $\quad$ Erofessional role model
- $\quad$ thical and legal framework practitioner

The most important aspects pertaining to LRIMC identified in the literature included:

- the physical lecture room environment

- psychological climate

- instructional objectives

- the choice of appropriate teaching strategies

- presenting the learning material

- $\quad$ educational media

- differentiated learning

- critical thinking

- motivation

- maintaining discipline

- $\quad$ stress and conflict management

- $\quad$ effective time management

- managing the administration of the lecture room

- the personal life of the NNE.

Each aspect was investigated and competence criteria pertaining to each specific aspect were then established (Curzon 1990; Heimlich \& Emmalou 1994: Kruger \& Van Schalkwyk 1993; Mellish, Brink \& Paton 1998; Quinn 1995; Slavin 1995).

The influences of mentorship and reality shock on the NNEs' competence in LRIM were also investigated. Many NNEs might experience reality shock, or transition trauma, in making the transition from student nurse educators to NNEs. The disillusions encountered during reality shock might be sufficient to make some NNEs leave the teaching situation (Marso 1987:54; Schaffer, Stringfield \& Wolfe 1992:183). In most cases where specific mentors were assigned to specific NNEs, the impact of reality shock seemed to be reduced. Guidance and support by mentors appeared to facilitate NNEs' adaptation to the teaching situation and to acquire LRIMC more rapidly than NNEs without mentors (Stallion \& Zimpher 1991:45).

\section{Research Design}

As no previous research could be traced about the LRIMC of NNEs, an in-depth literature search was conducted to identify components of LRIMC of NNEs to be included in the questionnaires. Thereafter an exploratory quantitative survey was adopted for exploring the dimensions of LRIMC of NNEs in the RSA, as no previous studies in the RSA could be traced which addressed these competencies. It was quantitative because attempts were made to analyse the specific numbers of responses to specific items on the questionnaires. This design was approved by the authorities requested to grant permission for data collection in institutions under their jurisdiction.

\section{Research questions}

NNEs enter the nursing education profession after complying with the minimum requirements set by the South African Nursing Council (SANC), as well as by the university where the novice has completed the programme. Questions about the LRIMC of NNEs which this research attempted to answer, included:

- Which competencies are expected from NNEs? (Literature review: items included in the questionnaires)

- How do NNEs view their own LRIMC? (Questionnaire 1)

- Does mentorship influence the adaptation of the NNEs to their new teaching roles? (Questionnaire 1)

- Do these NNEs have mentors that accompany them during the initial period of instruction? (Questionnaire 1)

- Do NNEs suffer from reality shock during their initial teaching experiences? (Questionnaire 1)

- How do NNEs' mentors view their LRIMC? (Questionnaire 2)

- How do NNEs' students rate the NNEs' LRIMC? (Questionnaire 3)

\section{Research instrument}

Three questionnaires, containing similar structured and semistructured questions, based on the literature reviewed, were designed and used to gather data about the LRIMC of NNEs, as perceived by the

NNEs themselves

their students

their mentors.

The questionnaires consisted of various sub-sections namely

- $\quad$ personal (biographical) information of the respondents

- $\quad$ orientation and guidance received from/provided by mentors (excluded from students' questionnaires)

- $\quad$ professional growth of NNEs

- the respondents' views on the NNEs' competence in the identified aspects of LRIM (as mentioned under 
the literature review). In this section a semantic differential scale of 1 (totally incompetent) to 5 (highly competent) was used.

The questionnaire designed for the NNEs also contained questions attempting to identify the NNEs' own views of their experiences and specific difficulties the NNEs might have encountered with different LRIM aspects.

\section{Pretesting, reliability and validity of the questionnaire}

The reliability of a research instrument refers to the consistency with which it measures the concepts of interest. Reliability testing focuses on stability, equivalence and homogeneity (Burns \& Grove 1999:257). Experienced nurse educators and a statistician evaluated the items as being relevant to specific research questions. Most items were obtained from the literature review - tested by other researchers. During pre-testing no problems were identified which could have influenced the reliability of the research instrument. It is conceded, however, that the five-point scale used to measure the NNEs' LRIMC might have been interpreted differently by different participants. Ideally these reported levels of LRIMC should have been compared with checklists completed during actual observations, but that proved to impossible during this survey.

The validity of an instrument is a determination of the extent to which the instrument actually reflects the abstract construct (or concept) being examined. Validity, like reliability, is not an all-or-nothing phenomenon, but rather a matter of degree... Validity will vary from one sample to another and from one situation to another (Burns \& Grove 1999:260). In this survey content-related validity was obtained by including the major concepts relevant to LRIMC as identified during an in-depth literature review. Face validity was evaluated by experienced nurse educators and by the participants in the pretest. Concurrent validity could be deduced because no major discrepancies arose between the LRIMC of NNEs' as reported by the NNEs themselves, their students and their mentors.

The questionnaire was pretested by a limited number of persons who did not form part of the research samples but who represented the three research groups, namely three NNEs, three mentors and ten student nurses. The questionnaire was comprehensive and took approximately 45 minutes to complete. Minor corrections and simplifications were implemented as a result of the pretest. The questionnaires were translated into Afrikaans by a professional translator. Five senior nurse educators, teaching in both English and Afrikaans for a minimum of five years, checked the versions of both languages for the accuracy of the translations of both the questionnaires and the covering letters. These letters explained the nature and the importance of the research, and guaranteed the confidentiality and the anonymity of the respondents.

\section{Research population and samples}

The research population consisted of all novice nurse educators, teaching student nurses in colleges and universities in the RSA for a period not exceeding two years. It was not possible to identify this population by extracting the persons' names who registered "nurse educator" as an additional qualification with the SANC during the preceding two years, because not all these persons were actually teaching student nurses. Letters were sent to the head of each of the identified 55 nursing schools (colleges and university departments) in the RSA, requesting them to identify any educator appointed at their nursing schools during the preceding two years, as well as any mentors assigned to such NNEs. Despite having sent reminders and pursued telephonic follow-up actions, only 36 nursing schools responded identifying 110 NNEs and 34 mentors. Questionnaires were distributed to the

- identified population of 110 NNEs

- population of 34 mentors

- 550 students (five students for each identified NNE who volunteered to complete the evaluative questionnaires in response to the principal's requests.

It is conceded that there could be no guarantee that the answers of those students who volunteered to complete evaluation forms would be similar to those of students who did not volunteer. However, these volunteers' responses were accepted as indicators of the NNEs' LRIMC as perceived by student nurses. Random sampling procedures of all students taught by NNEs proved to be impractical. The institutions were not able to supply complete lists of the students (population) concerned nor of participating in random sampling procedures due to pressures of time, lack of staff and undergoing restructuring processes.

Despite repeated follow-up actions, the responses remained poor, comprising:

$$
\begin{aligned}
& \text { - } \quad 32 \text { out of } 110 \text { NNEs }(29.09 \%) \\
& \text { - } \quad 18 \text { out of } 34 \text { mentors }(52.94 \%) \\
& 160 \text { out of } 550 \text { students }(29.09 \%) \text {. }
\end{aligned}
$$

\section{Statistical processing of questionnaires}

Data was coded and fed into the Statistical Analysis System (SAS) computer progamme by the personnel of Unisa's Department of Computer Services. Data analysis tests such as T-tests, F-tests, Bonferoni tests, ANOVA and MANOVA tests were done to test for significant differences between the three categories of respondents (NNEs, mentors and students). Due to limited space, the results of these statistical tests will not be provided in this article, merely the most important findings portrayed by utilising these tests.

\section{Research results Biographical data}

The average age of NNEs was 37 years, but their ages ranged from 26 to 57 . This indicated that mature persons with substantial clinical experience entered the teaching profession. Indeed 54 percent of these NNEs had experience as clinical instructors.NNEs with a number of years' experience prior to entering the teaching field, could be expected to be competent in LRIM, especially in applying theoretical concepts to clinical practice in meaningful ways.

Surprisingly 75 percent of the NNEs possessed degrees con- 
trasting with 50 percent of the mentors. Based on educational differences, with graduates having completed more liberal education than diplomates, graduates could be expected to be more competent in LRIM than the diplomates. Only eight NNEs had diplomas, therefore no meaningful comparisons could be made between the perceived LRIMC of diplomates and graduates.

\section{Mentorship}

Only 56 percent of the NNEs indicated that they had mentors who accompanied them during the initial stages of entering the teaching profession. No NNE indicated that he/she received any formal orientation nor regular supervision. (Similar findings were reported in Australia by Stallion \& Zimpher 1991:42).

\section{Reality shock}

All NNEs experienced some degree of reality shock on entering the teaching situation:

- 56 percent were unsure as to whether or not the exist-
ing staff members welcomed them
28 percent experienced the first teaching situation as
being "overwhelmingly frightening"
37.5 percent felt that they were no longer in control,
and that they could not cope with the demands of the
teaching situation. NNEs underestimated the amount of time required to fulfil the numerous administrative tasks, and to expand their knowledge bases. More teaching experience prior to entering the first real teaching situation would have reduced the impact of reality shock - according to the NNEs' perceptions. Effective mentorship also assisted NNEs in coping with reality shock, mainly because the mentors were available to evaluate the standard of their preparations and the quality of their lectures/presentations.

\section{Lecture room instructional management competencies of the NNEs}

Findings also indicated that a significant difference existed between the lecture room competence views of NNEs with and those without mentors. This was indicated in every aspect of LRIM competence. NNEs emphasised the need for support and accompaniment by senior members of staff.

Particular aspects of NNEs' LRIMC that needed to be addressed included adequate subject knowledge bases, greater efforts with the preparation of media, making more effective use of differentiated learning, motivation, discipline, critical thinking, problem solving, and maintaining discipline in the lecture rooms. Mentors indicated that NNEs did not invest sufficient effort into preparing their lectures. Preparation seemed to be haphazard with uninteresting media which were carelessly prepared and underutilised. The NNEs' subject knowledge bases for the lectures seemed to be inadequate. Apparently no additional research was done to keep up to date with the latest trends in the specific subject, oversimplified facts were presented at a lower levels than the students' capabilities, and textbook information was mostly presented. Individual needs, cultural differences and aspects that could foster caring climates in lecture rooms were generally not addressed by the NNEs. Successful theory-practice integration was almost non-existent. Students were bombarded with cognitive facts without integrating aspects from the psychomotor and affective domains. When opportunities arose during instruction, creativity and critical thinking were not promoted. Opportunities to stimulate problem solving during the lectures were not utilised. NNEs were mainly instructing students for summative evaluation purposes, for passing tests and examinations, rather than for mastering cognitive knowledge to integrate into their clinical practice situations.

The difference in competence views between first and second year NNEs indicated that professional growth positively influenced their LRIMC. Contrary to what was expected clinical experience did not influence the LRIMC of NNEs, because the majority of the NNEs failed to integrate theory and practice despite considerable clinical experience accumulated prior to entering the teaching situation. (This apparent lack of integration of theory and practice would warrant further investigations).

NNEs were also asked to indicate how they viewed their own professional growth. Thirty four percent indicated that they were becoming good nurse educators, and that they would soon be competent. Another 34 percent indicated that they had acquired sufficient experience to be good educators. Only 6 percent indicated that they perceived themselves to be incompetent educators.

NNEs compared themselves to other NNEs revealing that

- 62 percent considered themselves to compare well with other NNEs

- 18 percent indicated that they were performing better than other NNEs.

NNEs were also asked whether they were satisfied with the academic quality of their preparation as nurse educators. Although 87 percent indicated that they were satisfied, they indicated the need for more teaching experience prior to entering the actual teaching situations.

\section{Conclusions and limitations of the research: Recommendations for future research}

This research concluded that NNEs were not perceived to be competent in any of the 17 identified roles. They needed further experience in most aspects of LRIM. They also required much support and supervision from their mentors who needed to be orientated about the importance of mentorship. It is strongly advised that every NNE should have a specific mentor during the first year of his/her teaching career.

Effective use of lecturing time, differentiated learning, problem solving and critical thinking, and the importance of fostering a caring climate should be incorporated in NNEs' lectures and in their orientation programmes. Effective preparation and use of teaching media should be stressed. 
NNEs clearly expressed their need for more teaching exposure, and it is recommended that nursing schools participate in the education and training of these students. Furthermore, in-service education and peer group facilitation, should assist NNEs to adapt to the teaching environment and to the teaching activities.

It is also recommended that a similar study on more advanced nurse educators' LRIMC should be undertaken to establish the competence of nurse educators in general, and that a similar study should be conducted on the competence of clinical instructors. Special emphasis should be placed on evaluating the NEs' competence in integrating theory and clinical practice, stimulating critical thinking and problem solving, using differentiated learning, and fostering cultural sensitivity amongst students..

Limitations of the study included the low response rate due to the sensitive nature of the study as well as the voluminous questionnaires. Ideally all NNEs should have been observed, but this was impossible due to financial and logistic constraints. Future surveys could strive to contrast and/or correlate the perceptions portrayed on questionnaires with evaluations done by the researcher(s) during actual teaching sessions.

Regardless of the factors influencing the competence of NNEs, this study indicated that NNEs in the RSA were not perceived to be competent when they started teaching. This matter is of critical concern for the success of the nursing profession and has implications for the public as well. To become future competent professional nurses requires that the current student nurses in this country should be taught by competent nurse educators. This is crucial to ensure optimal nursing care, and to meet the demands that health care poses on the nursing education system. The nurse educators in the RSA should also implement all means available to ensure that student nurses receive the best possible education to prepare them for their professional roles.

The roles, outcomes, competencies and evaluation criteria established in this study could serve as a guide to departments of nursing sciences at universities in the RSA to educate and train their student nurse educators to become more competent NNEs. The in-service training programmes of nursing schools should enable NNEs to acquire the necessary competence, self-confidence and self-actualisation to attain and maintain LRIMC, essential for equipping the student nurses of the RSA for their roles as professional nurses. The LRIMC of NNEs is pivotal to the quality of nursing care rendered in the RSA. Davis et al (1992:160) concluded that ... the preparation for the faculty role is not only a critical concern to the success of the novice faculty member and to the profession, but has implications for the public.

\section{List of references}

BURNS, N \& GROVE, SK 1999 : Understanding nursing research. $2^{\text {nd }}$ ed. Philadelphia: Saunders.

CURZON, LB. 1990. Teaching in further education. $4^{\text {th }}$ Edition. Wiltshire: Cassell.

DAVIS, DC; DEARMAN, C; SCHWAB, C \& KTCHEN, E 1992 : Competencies of novice nurse educators. Journal of Nursing Education. 31(4):159-164.

HALSTEAD, JA; RAINS, JW; BOLAND, DL \& MAY, FE 1996 : Reconceptualizing baccalaureate nursing education: outcomes and competencies for practice in the $21^{\text {st }} \mathrm{Cen}$ tury. Journal of Nursing EducationaI. 35(9):413-416.

HEIMLICH, JE \& EMMALOU, N 1994 : Teaching styles in adult education. San Francisco: Jossey-Bass.

KRUGER, AG. \& VAN SHALKWYK, OJ. 1993. Classroom management. Pretoria: Academica.

MARSO, RN 1987 : Differences between self-perceived job expectations and job realities of beginning teachers. Journal of Teacher Education. November-December:53-56.

MELLISH, JM., BRINK, HIL. \& PATON, F. 1998. Teaching and learning the practice of nursing. $4^{\text {th }}$ Edition. Johannesburg: Heinemann.

QUINN, FM 1995 : The principles and practice of nurse education. $3^{\text {rd }}$ Edition. London: Chapman \& Hall.

REYNOLDS, A 1992 : What is competent teaching? A review of the literature. Review of Educational Research. 62(1):1-35.

SCHAFFER, E; STRINGFIELD, S \& WOLFE, D 1992 : An innovative beginning teacher induction program: a twoyear analysis of classroom interactions. Journal of Teacher Education. 43(3):181-192.

SLAVIN, RE 1995 : A model of effective instruction. The Educational Forum. 59:166-176.

STALLION, B \& ZIMPHER, P 1991 : Classroom management intervention: the effects of training and mentoring on the inductee teacher's behaviour. Action in Teacher Education. 13(1):42-49. 